\title{
Lion Hunting and Trophy Quality Records in Zambia for the Period 1967-2000: Will the Trends in Trophy Size Drop as Lion Population Declines?
}

\author{
Chansa Chomba ${ }^{*}$, Ramadhani Senzota ${ }^{2}$, Harry Chabwela ${ }^{3}$, Vincent Nyirenda ${ }^{4}$ \\ ${ }^{1}$ School of Agriculture and Natural Resources, Disaster Management Training Centre, Mulungushi University, \\ Kabwe, Zambia \\ ${ }^{2}$ Department of Zoology and Wildlife Conservation, University of Dar es Salaam, Dar es Salaam, Tanzania \\ ${ }^{3}$ Department of Biological Sciences, University of Zambia, Lusaka, Zambia \\ ${ }^{4}$ Zambia Wildlife Authority, Chilanga, Zambia \\ Email: ${ }^{*}$ chansachomba@rocketmail.com, ${ }^{*}$ ritachansa@yahoo.com
}

Received 7 January 2014; revised 7 February 2014; accepted 15 February 2014

Copyright @ 2014 by authors and Scientific Research Publishing Inc.

This work is licensed under the Creative Commons Attribution International License (CC BY).

http://creativecommons.org/licenses/by/4.0/

(c) (1) Open Access

\section{Abstract}

Data on lion skull measurements taken were collected and analyzed to determine trends in trophy size as an indicator of population size, and area of origin among the concessioned hunting areas in Zambia for the period 1967-2000. A comparison of trophy quality was also made with Tanzania and Zimbabwe which were the other two key sources of lion trophies in Africa. It was assumed that a comprehensive analysis of lion trophy sizes obtained from trophy hunting would be used as an indicator of hunting pressure on lion populations in Zambia. This approach was used because trophy size is an index of abundance particularly for species such as lion which are difficult to count using conventional census methods. Record lion trophies from Safari Club International rating were also collected and assessed to compare trophy quality obtained from Zambia and those of Tanzania and Zimbabwe for the same period 1967-2000 (33 years). Results obtained suggested that Zambia's contribution to the record trophies under Safari Club International did not decline in the intervening period 1967-2000 and could not be used as an effective indicator of lion population in Zambia. At regional level, Zambia had second highest $24 \%$, after Tanzania $56 \%$, while Zimbabwe was third, $\mathbf{2 0 \%}$. It was found that the size of skulls could not be used as an effective indicator of population size as the record trophies did not decline while the population was alleged to have declined on the continent. Other factors, such as genetic, low prey densities, snaring, poisoning and problem animal control needed to be investigated to determine their impact on

${ }^{*}$ Corresponding author.

How to cite this paper: Chomba, C., et al. (2014) Lion Hunting and Trophy Quality Records in Zambia for the Period 1967-2000: Will the Trends in Trophy Size Drop as Lion Population Declines? Open Journal of Ecology, 4, 182-195.

http://dx.doi.org/10.4236/oje.2014.44019 


\section{the lion population status.}

\section{Keywords}

\section{Lion; Trophy; Measurement; Trend; Decline; Population Size}

\section{Introduction}

The African lion (Panthera leo) has recently emerged as a species of global conservation concern [1]. Two independently compiled estimates concluded that lion populations throughout Africa numbered from ca. 20,000 [2] to 40,000 individuals [3]; a precipitous decline from population estimates as high as 100,000 lions less than ten years ago [4]. Although this early estimate has been questioned, lions are widely believed to have declined drastically over much of their former range [3] [5] (Figure 1(a)). The nearly two-fold discrepancy in the recent estimates underscores the lack of reliable data regarding current status of the species throughout its range. Such population estimates have been disputed by many scientists who claim that this would be a gross underestimate and the conservation of the African lion has continued in an environment of inadequate and unreliable data regarding the current status of the species throughout its range. In Zambia, there are conflicting statements on the national population estimate provided by different researchers. In 2002 [2] an estimated number of $1500 \pm 500$ individuals was provided whilst another estimate gave a higher figure of 3575 [3] which despite being higher than the earlier estimate [2] was still said to be an underestimate [3] given the lion's wide distribution in the country (Figure 1(b)).

The continued inadequate and unreliable quantifiable information has created difficulties among lion range states and international conservation organizations such as the Convention on International Trade in Endangered Species of Wild Fauna and Flora (CITES). Range states and international organizations do not usually agree on whether to continue or suspend the consumptive utilization of the lion as the case was in October 2004 at CITES $13^{\text {th }}$ Conference of the Parties (COP 13) in Bangkok Thailand. At COP 13 a proposal was made by the Republic of Kenya to uplift lion from Appendix II to Appendix I of CITES. Countries such as Zambia where lion hunting was still taking place contested this proposal and asked the international scientific community to thoroughly examine the factors causing the alleged precipitous decline rather than isolating trophy hunting to be the only cause.

As a consequence of that request which was made by Zambia and other Southern African Countries, the World Conservation Union (IUCN)’s Species Survival Commission's Cat Specialist Group, Wildlife Conservation Society, African Lion Working Group, and Africa Resources Trust conducted two workshops in Cameroon in October 2005 and South Africa in January 2006. The workshops facilitated compilation of all available data on the current status of the African lion, and encouraged African range states to develop regional and country specific lion conservation strategies. A major out come of these workshops was a range-wide priority setting exercise (RWPS) that identified habitat loss, declines in wild prey populations, and human-lion conflict as primary threats to the remaining lion populations [6].

Despite the uncertainty on the accuracy and precision of the lion population estimates in Africa, it is assumed that Zambia's centralized geographic location; vast tracts of high-quality wilderness and low human population density render it a potential stronghold for the remaining lion populations in southern Africa. Yet as in many other countries, little is known about the current status of lions in Zambia, let alone the impact of trophy hunting. The estimates provided in 2002 [2] have been questioned, because they were derived from an approach that combined three areas of different habitats. The potential for error was high when extrapolating predator densities obtained from small, high-density areas [7]-[9]. In addition to habitat type, lion density would be expected to vary regionally across land use areas, and seasonally with prey abundance and distribution [9]-[12]. On the other hand, Chardonnet [3] utilized a finer-scale resolution to produce an estimate of 3575 lions in Zambia, but for some areas their calculations relied on lion densities recorded nearly 40 years ago [13]. Given the global [14] [15] and continental [16] [17] declines of large carnivore populations over the same period, it is unlikely that historic numbers accurately describe current status. Thus, reliable data on current lion occurrence, distribution, and abundance in Zambia still remain a critical area requiring further research.

Adding to the sense of urgency, it was the fact that trophy hunting of lions in Zambia represents a very important 


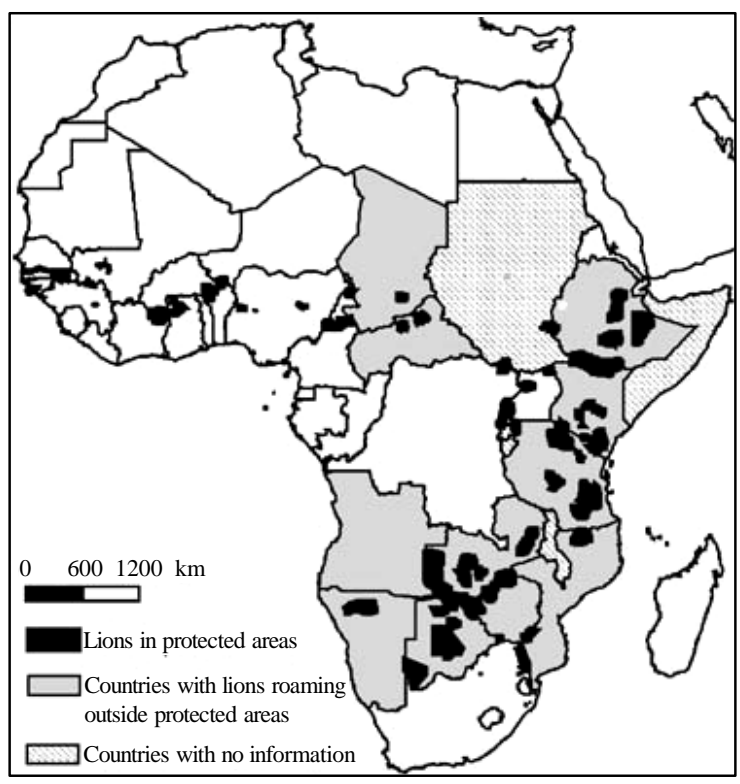

(a)

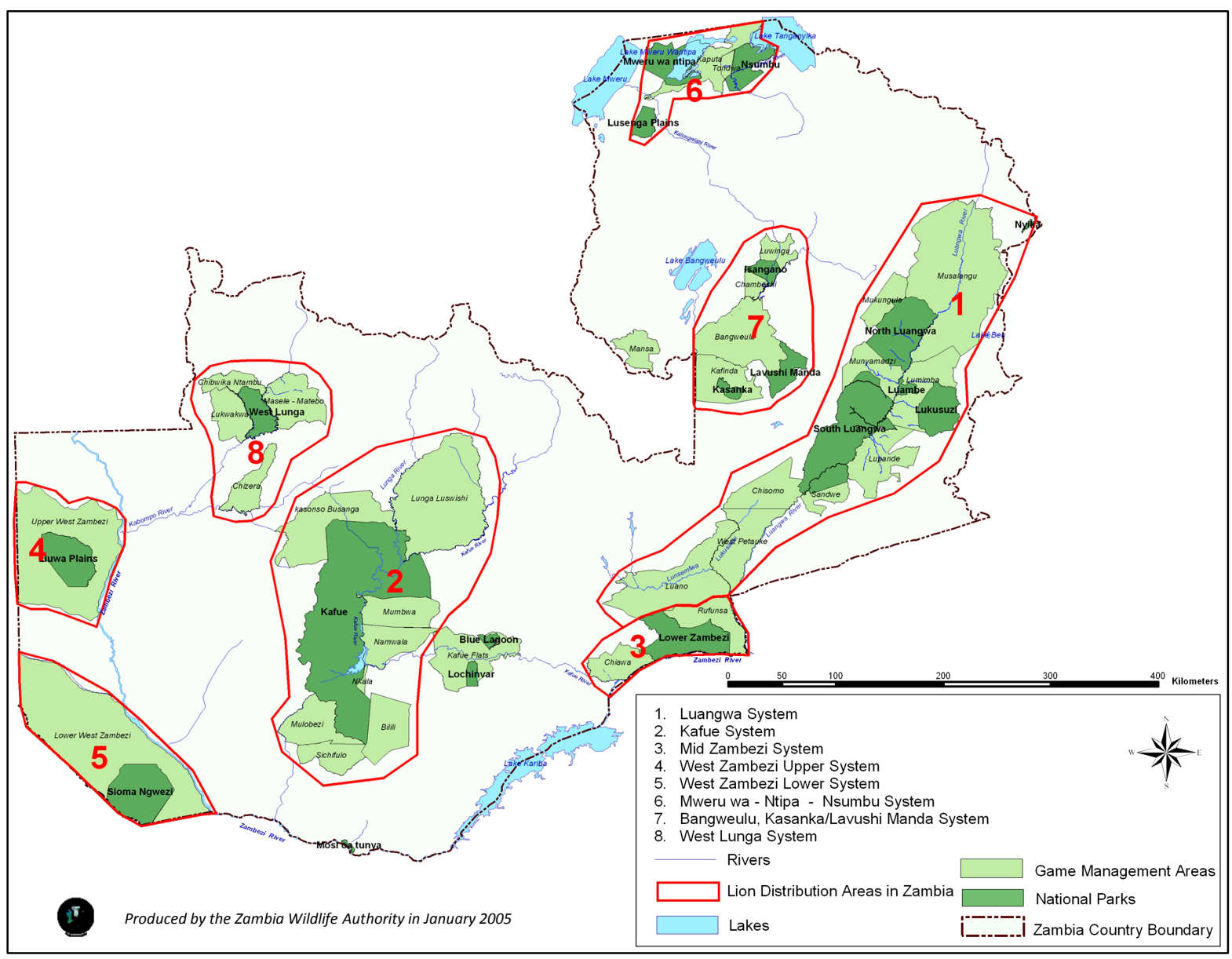

(b)

Figure 1. (a) Map of Africa illustrating location of major lion populations (Modified after Van Der Merwe and Bauer, 2004). Areas not shaded with black colour in Zambia do not entail complete absence but carry marginal populations; (b) Lion conservation clusters/units in Zambia (Source: Zambia Wildlife Authority, 2005). 
source of revenue for Zambia Wildlife Authority (ZAWA) and local communities, and is also rated one of the top four lion-trophy producing countries in the world together with Tanzania, Zimbabwe and South Africa [18]. Healthy lion populations can therefore, support well-regulated and managed trophy hunting. In fact, the income gained through commercial hunting provides economic incentives for rural communities to tolerate, even help conserve lions. However, unsustainable levels of trophy hunting, or untimely removal of breeding males, can trigger lion population decline through social disruption and infanticide [18]-[21]. Studies in Tanzania for instance, found that selective harvesting of older ( $>5-6$ years old) males produced maximum off-take of trophy animals while reducing male turnover rate, since most males over five years of age have already bred and are no longer in charge of a pride. By reducing male turnover, infanticide often caused by incoming males is also reduced, thus the negative effect on the remaining population is minimized [22] (Figures 2(a)-(d)). This way, well managed trophy hunting becomes a useful management tool.

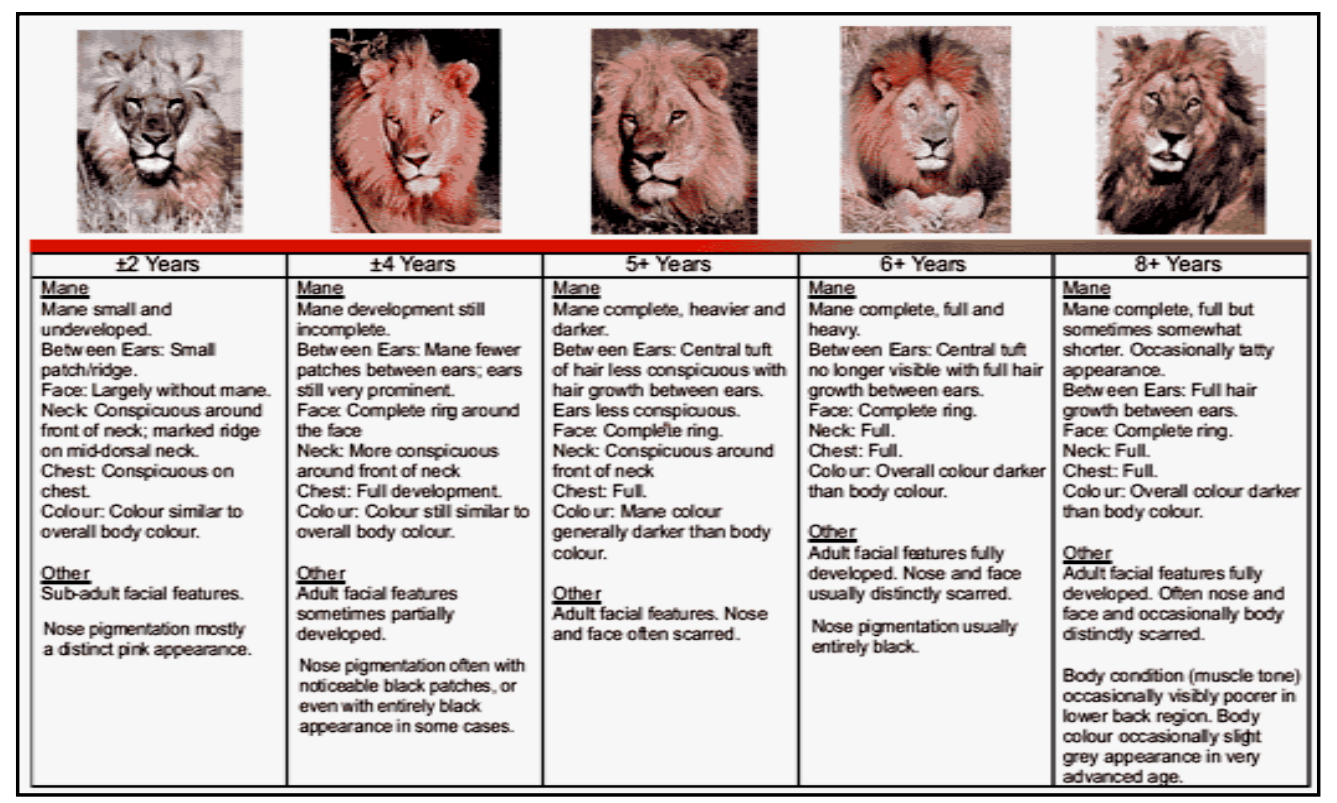

(a)

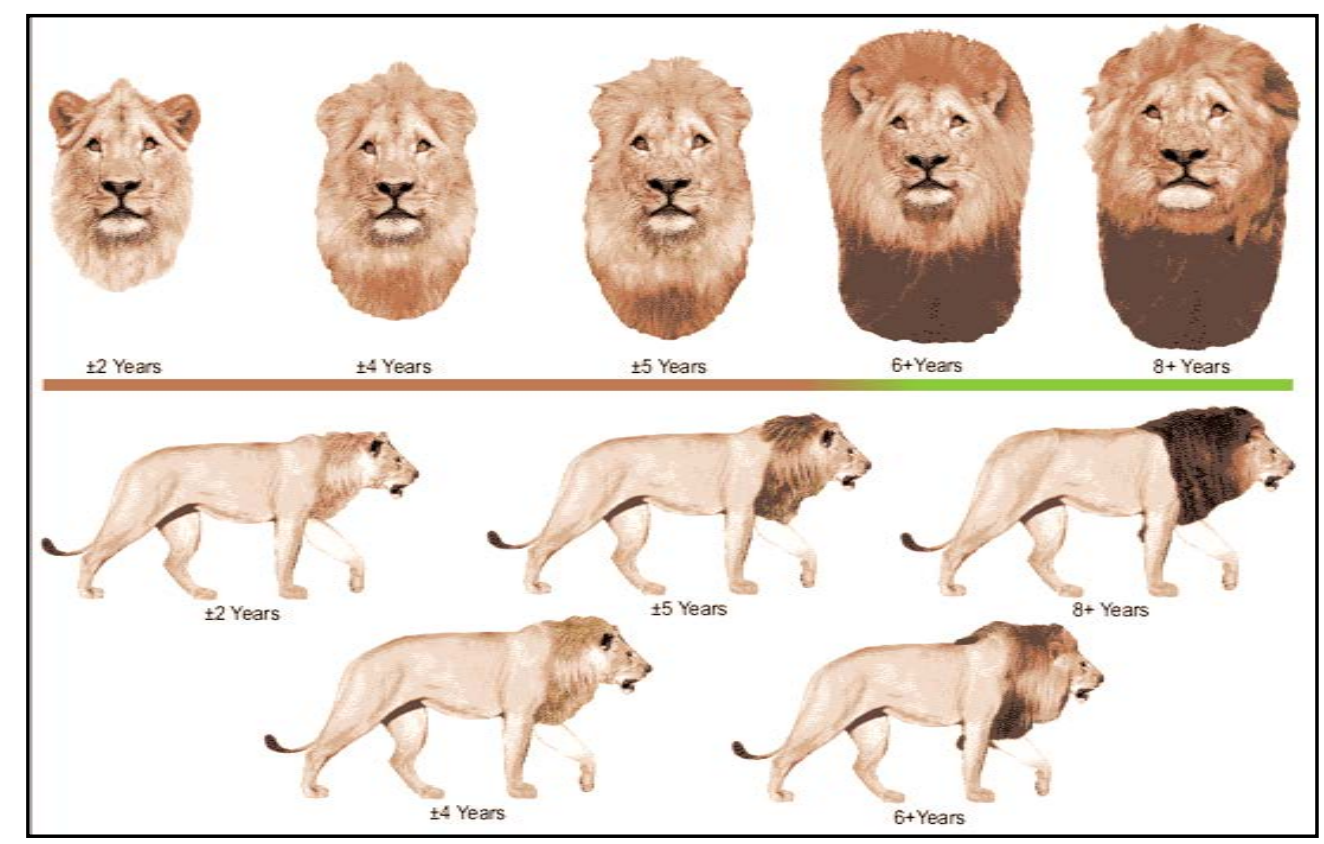

(b) 


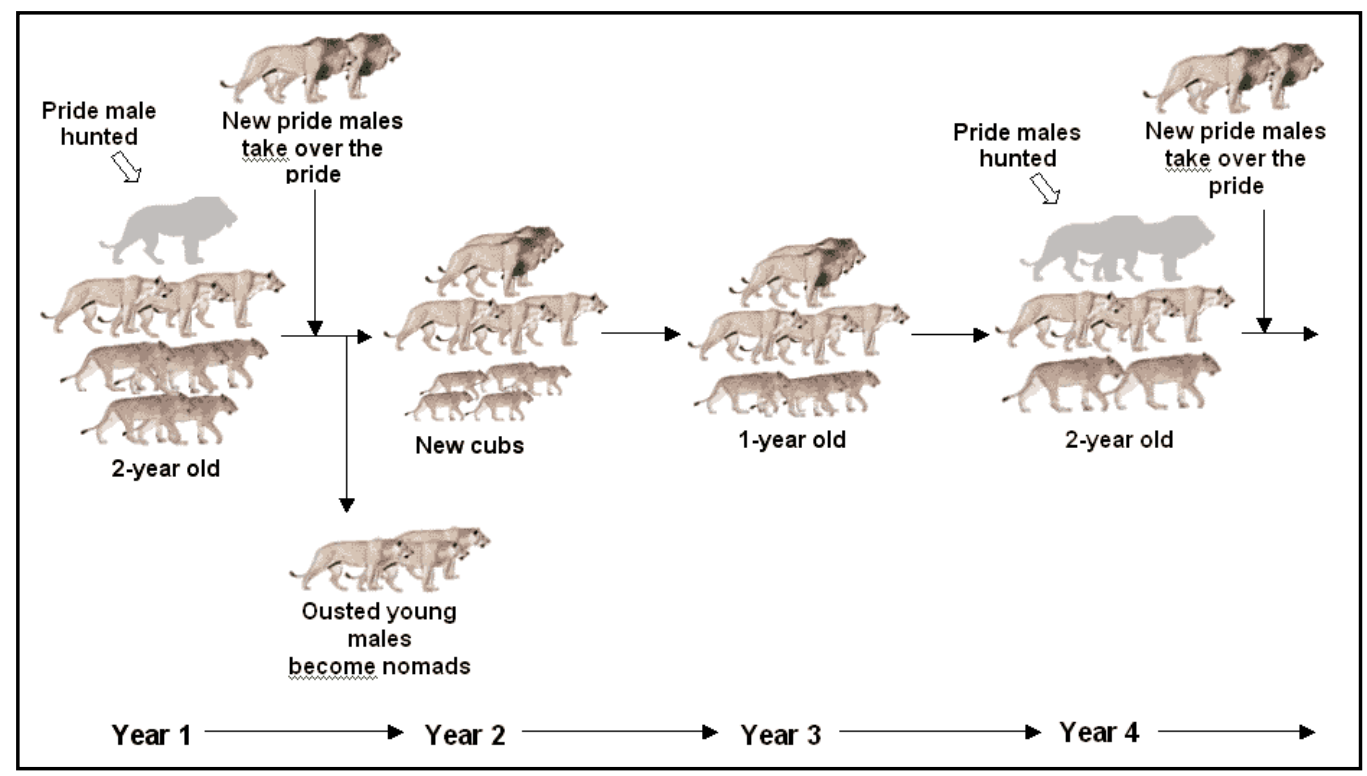

(c)

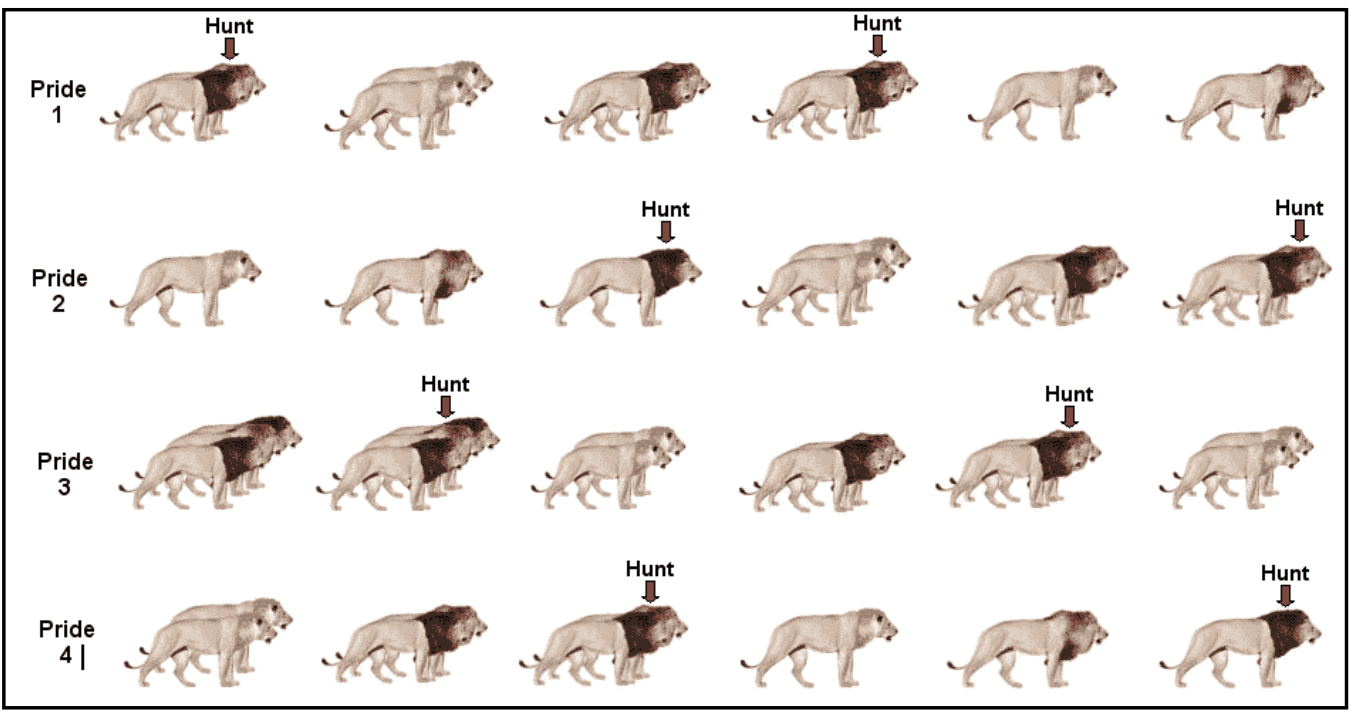

(d)

Figure 2. (a) Trophy hunting based on trophy size and appearance of mane; (b) Trophy hunting based on trophy size and general appearance; (c) Conceptual male off-take at pride level; (d) Conceptual removal of males at hunting block/Game Management Area level (Modified after, Attwell and Viljoen, 2008).

The solution to current data deficiency of population estimates in Zambia was to initiate field studies to collect accurate estimates of lion population size, demographics, and productivity upon which sustainable quotas could be based. Empirical data sets on aging of trophy lions in the field, would also aid development of a selective age based hunting program. In response to this demand, ZAWA partnered with the Zambia Lion Project (ZLP) in 2003 and African Large Carnivore Project in 2007. In 2004, the ZLP began obtaining genetic samples (DNA) from lions taken as trophies in GMAs. Such samples were sent to the Conservation Genetics laboratory, Center for Tropical Research, University of California Los Angeles in the United States of America.

Preliminary results from the first 19 samples were obtained in March 2006. These results suggested that the Luangwa Valley lions were relatively diverse genetically, with multiple matrilines contributing trophy males to the population. So the suspicion of inbreeding was eliminated.

Further samples have since been collected and are currently undergoing microsatellite and mitochondrial 
analysis. It is assumed that these additional samples will facilitate estimation of population size and assignment of trophy males to their birth prides, thereby providing information on movements (dispersal) of males between National Parks and Game Management Areas. A second level of genetic investigation is to assess Zambia's lions on a national scale. Genetic profiles of lions from three disjunctive areas, of the Luangwa Valley, Lower Zambezi and Kafue, which will be compared to determine gene flow, or confirm any genetic isolation of lions residing in these areas.

Such results, together with recent genetic analyses of lion population structure, size, and dispersal in a dense habitat of Tanzania’s Selous Game Reserve [23] [24] will enable Zambia to have more accurate and reliable data bank. When such results have been made available, the government would then make an informed decision based on empirical evidence.

Regarding the impact of trophy hunting, a program to selectively target older males in trophy hunting was being developed by ZLP. The Zambia Wildlife Authority, Professional Hunters Association of Zambia (PHAZ), and the Safari Hunters Outfitters Association of Zambia (SHOAZ) working with ZLP were engaged in developing a program of age-based selective hunting in Zambia. This effort took into account the protocol in Tanzania where coloration of the nose pad and extent of mane development [25]-[27] were being used.

Since Visual characteristics, including mane size and development, are known to vary by region, ZLP employs x-ray analyses of a premolar tooth to examine the extent of the pulp cavity, and cementum annuli ring counts which provides age category of young, sub-adult, and adult. It is hoped that a consistency of data collection will permit robust comparison of results which will provide useful information for the trophy hunting industry as population models indicate that the loss of males through trophy hunting of older males ( $>5$ years of age) has minimal impact on the remaining lion population [28] (Figures 2(a)-(d)).

These studies when concluded by 2013/2014 or thereafter, are expected to dispel the suspected negative impact of trophy hunting on lion population. In particular, selective removal of older males which is recorded to have minimal disruption effect on pride structure, reproduction, and cub survivorship as confirmed by studies where it was shown that removal of older ( $\geq 6$ years) lions as trophies had minimal negative impacts on the remaining population [28] [29].

Given that the results of the studies by ZLP and ALCP will take time before results could be made available to decision makers, the setting of off-take quotas for the lion has continued to be controversial with Safari Hunting Operators always demanding a higher quota while the non-consumptive tour operators contest that hunting would reduce lion populations and negatively affect the non-consumptive tourism industry and have always tried to lobby for a moratorium on lion hunting, which was achieved in 2012 when government again banned trophy hunting.

In light of the expanding non consumptive tourism and their strong advocacy to stop lion hunting and media reports that lions have drastically declined in Zambia, it became necessary for us to provide a historical perspective of how Zambia has performed in the area of producing SCI record lion trophies, and which areas of the country produced the most record lion trophies.

It was assumed that if Zambia was found to be producing inferior lion trophies in the region, it would justify the national moratorium on lion hunting.

Since lion alone generates on the average above US\$200,000 revenue per year for ZAWA and local communities, it is necessary to delve into its historical performance in the country and at regional level. This study therefore, assessed the following; 1) number of trophy records and years when Zambia contributed to the Safari Club International listing of record trophies in the last three decades; 2) hunting areas which contributed the most record trophies; 3) whether record trophy contribution to SCI declined over the last three decades; 4) Zambia's proportional contribution to (SCI) in comparison with Tanzania and Zimbabwe. The Republic of South Africa, was left out of this study because of the wide spread captive breeding of lions and also that a good portion of lion hunting takes place on Game Ranches. It was also alleged that canned lion hunts were common on Game Ranches. Botswana was also left out because it had already imposed a non-time bound hunting moratorium of lion.

This study focused on the period 1967-2000 and left out 2001-2013, because of the reorganization of the Department of National Parks and Wildlife Service (NPWS) into a semi autonomous Zambia Wildlife Authority (ZAWA) which epitomized in 2000. This was followed by hunting ban imposed by government for two consecutive years and another ban in 2012. 


\section{Materials and Methods}

Data on lion skull measurements for the period 1967-2000 were obtained from the archives, and these were verified by comparing with sets of data from Safari Club International Record Book of Trophy animals in Tucson Arizona in the United States of America.

Measurements were based on the Safari Club International (SCI) method 15 [30]. In this method, the length of skull is measured using a 5 metre steel tape. Two wooden 1 metre rulers are placed at the anterior and posterior end of the lion skull. Measurements are then taken in inches as recommended by SCI parallel to its longitudinal axis from the anterior to the posterior end of the skull. The width of the skull is measured by placing the two wooden rulers on each side of the skull at the edge of the zygomatic arch or cheek bones at right angle to the longitudinal axis. The measurement in inches is then taken across the zygomatic arches.

To obtain score when measuring in inches the record fraction is recorded in $1 / 16$ ths of an inch. Damaged skulls are usually left out as these would give erroneous records. For repaired skulls only original skull material from the same animal are measured, either in its original state or acceptably put back together so as not to increase any measurement. Any other material either natural or taxidermic that had been added to the skull is not measured. Information on the Game Management Areas (GMA) in Zambia from which the trophy records were hunted and years in which such records were posted was collected from the Zambia Wildlife Authority licensing archives and verified with the SCI record book. For Tanzania and Zimbabwe (Figure 3), all the data on the names of hunting areas from which the record trophies were hunted were obtained from the SCI record book.

\section{Results}

\subsection{Number of Trophies Contributed to SCI}

The total number of record lion trophies contributed to the SCI list of record trophies for the period 1967-2000 by Zambia, Tanzania and Zimbabwe was 45. Of this total, Tanzania contributed 25 (56\%), Zambia 11 (24\%) and Zimbabwe had 9 (20\%) (Figure 4). The contribution of record trophies varied between countries with Tanzania being in the lead, seconded by Zambia and Zimbabwe was last (Table 1; Figure 4).

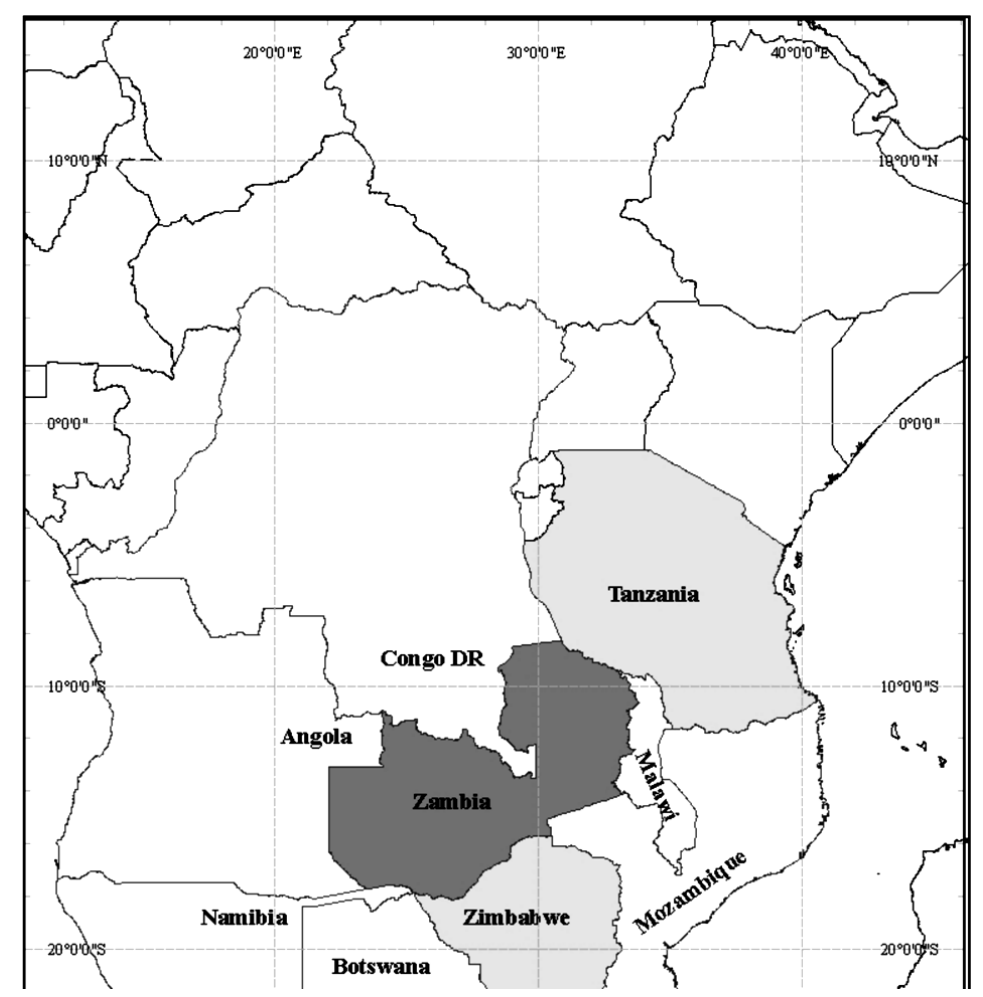

Figure 3. Location of Zambia, Zimbabwe and Tanzania where lion measurements were col- lected. 
Table 1. Safari Club International lion trophy records from Tanzania, Zambia and Zimbabwe, 1967-1999.

\begin{tabular}{|c|c|c|c|c|c|c|c|}
\hline \multirow[t]{2}{*}{ Name of client } & \multirow[t]{2}{*}{ Date } & \multicolumn{2}{|c|}{ Source of trophy } & \multicolumn{2}{|c|}{ Measurements (inches) } & \multirow[t]{2}{*}{ Score } & \multirow[t]{2}{*}{ Rank } \\
\hline & & Country & Area & Length of skull & Width of skull & & \\
\hline Fred Rademeyer & 1967 & Zambia & Mulobezi & $15^{12 / 16}$ & $10 \%$ & $25^{14 / 16}$ & 17 \\
\hline William A. Bond & 1972 & Tanzania & Selous & $15^{14 / 16}$ & 10 & $25^{14 / 16}$ & 17 \\
\hline Franscisco Urrea Jr. & 1975 & Zimbabwe & & $15 \%$ & $10^{15 / 16}$ & $26 \% / 16$ & 9 \\
\hline Pete Papac & 1979 & Zambia & Luangwa Valley & $15^{10 / 16}$ & $10 \% / 16$ & 26 & 15 \\
\hline Peter L. Horn II & 1980 & Zimbabwe & Kazungula & $16^{3} / 16$ & $10 \frac{1}{16}$ & $26 \frac{4}{16}$ & 11 \\
\hline George Blond & 1981 & Zimbabwe & & 15 & $10^{14 / 16}$ & $25^{14 / 16}$ & 17 \\
\hline Aldo Ravelli & 1981 & Zimbabwe & Mana-Angwa & 16 & 10 & 26 & 15 \\
\hline Bub Smith & 1982 & Zambia & Luangwa Valley & $16^{14 / 16}$ & $9^{11 / 16}$ & $26{ }^{2} / 16$ & 13 \\
\hline Ron Rismon & 1983 & Zimbabwe & Ngamo Forest & $15^{12 / 16}$ & $10 \% / 16$ & $26{ }^{2} / 16$ & 13 \\
\hline Paul Palmer & 1983 & Zimbabwe & Matesti & $15 \%$ & $10 \% / 16$ & $26 \frac{1}{1} 16$ & 14 \\
\hline William Mosesian & 1983 & Tanzania & Rungwa & 16 & 10 & 26 & 15 \\
\hline Eberhard Huser & 1983 & Zambia & Kafue River & $15^{12 / 16}$ & $10 \% / 16$ & $25^{14 / 16}$ & 17 \\
\hline Lad Shunneson & 1984 & Zimbabwe & Ngamo & $15^{15 / 16}$ & $10^{14 / 16}$ & $26^{14 / 16}$ & 11 \\
\hline Kurt Ziegler & 1984 & Tanzania & Mto wa Mbu & $15^{14 / 16}$ & $10 \% / 16$ & $26 \frac{4}{16}$ & 11 \\
\hline Creg Leerberg & 1984 & Zimbabwe & Mwenezi & $15^{14 / 16}$ & $10^{3} / 16$ & $26{ }^{1} / 16$ & 14 \\
\hline Bill Lambert & 1984 & Tanzania & Selous & 16 & 10 & 26 & 15 \\
\hline Paul Snider & Sept. 1985 & Zimbabwe & Deka & 16 & $10^{13 / 16}$ & $26{ }^{2} / 16$ & 13 \\
\hline Lance Sablich & 1986 & Zambia & Mumbwa west & 16 & $10 \%$ & $25^{15 / 16}$ & 16 \\
\hline Hugh Jacks & 1986 & Tanzania & Moyowosi & $15 \% / 16$ & $10^{12 / 16}$ & 26 & 15 \\
\hline Wayne Pensenstadler & 1986 & Tanzania & Selous & 16 & 10 & 26 & 15 \\
\hline Richard Wayne Parker & 1986 & Zimbabwe & Matesti & $15^{8} / 16$ & $10 \% / 16$ & 26 & 15 \\
\hline Robert Hawkey & 1986 & Zambia & Luangwa valley & $15 \% / 16$ & $10^{14 / 16}$ & $26{ }^{4} / 16$ & 11 \\
\hline Dwight E. Farr Jr. & 1987 & Zimbabwe & Chete & $16 \%$ & $10 \% / 16$ & $264 / 16$ & 11 \\
\hline Randy House & 1987 & Tanzania & Ruaha & $15 \% / 16$ & 11 & $26 \frac{4}{16}$ & 11 \\
\hline Ulf Askert & 1987 & Zambia & Mulobezi & $14^{10} / 16$ & $11^{8 / 16}$ & $26{ }^{2} / 16$ & 13 \\
\hline Joy G. Cocke & 1987 & Tanzania & Selous & $15^{13} / 16$ & $10^{10} / 16$ & $25^{15 / 16}$ & 16 \\
\hline Gary Walker & 1988 & Zambia & Mumbwa west & $15^{14 / 16}$ & $103 / 16$ & $26 \frac{1}{1} 16$ & 14 \\
\hline Cynthia Saizhauer & 1989 & Tanzania & Selous & $15^{7} / 16$ & $10 \% / 16$ & 26 & 15 \\
\hline Jim Loeffer & 1990 & Zimbabwe & Malapati & $15^{12 / 16}$ & 11 & $26^{12 / 16}$ & 4 \\
\hline William Mosseian & Aug. 1990 & Tanzania & Selous & $16 \%$ & $10^{1 / 26}$ & $26 \% / 16$ & 9 \\
\hline Marvin G. Pipkin & 1991 & Tanzania & Loliondo & $15^{14 / 16}$ & 11 & $26 \% \frac{5}{16}$ & 10 \\
\hline James H. Harrison & 1991 & Tanzania & Loliondo & $16 \frac{4}{16}$ & $10 \% / 16$ & $26{ }^{2} / 16$ & 13 \\
\hline Wally Dallenbach & 1993 & Zimbabwe & Ngamo Forest & $15 \%$ & $10^{10 / 16}$ & $26 \% \frac{3}{16}$ & 12 \\
\hline Bernard van Doren & 1993 & Tanzania & Njingwe & $15^{13 / 16}$ & $10 \% / 16$ & $26^{1} /^{16}$ & 14 \\
\hline Jerry Jones & 1994 & Tanzania & Lukwati & $15^{10 / 16}$ & $10 \% / 16$ & $25^{15} / 16$ & 16 \\
\hline Eusebio Zuloaga & 1994 & Tanzania & Mbono & $16^{8} / 16$ & $10^{8} / 16$ & 27 & 2 \\
\hline Dick Cabela & 1995 & Tanzania & Fort Ikoma & $15^{8} / 16$ & $10^{8} / 16$ & 26 & 15 \\
\hline Eusebio Zuloaga & 1995 & Tanzania & Mbono & $16 \frac{4}{16}$ & $9^{12 / 16}$ & 26 & 15 \\
\hline Tom E. Smith & 1995 & Tanzania & Rungwa Ikili & 15 & 11 & 26 & 15 \\
\hline William Mosesian & 1996 & Tanzania & Kilombero & $16 \% / 16$ & $10 \% / 16$ & $26^{13 / 16}$ & 3 \\
\hline Dan Wintersteen & 1996 & Zimbabwe & Tsjolotjo & $15^{14 / 16}$ & $10 \% / 16$ & $26{ }^{2} / 16$ & 8 \\
\hline Hanley Sayers Jr. & 1996 & Tanzania & Melele & $15^{14 / 16}$ & $104 / 16$ & $26{ }^{2} / 16$ & 13 \\
\hline William Brisben & 1997 & Zambia & Mumbwa west & $16 \% / 16$ & $10 \% / 16$ & $26^{10 / 16}$ & 5 \\
\hline Chad Brisben & 1997 & Zambia & Mumbwa west & $15 \% / 16$ & $10^{11 / 16}$ & $26 \frac{1}{1} 16$ & 14 \\
\hline Jack Fiske & 1998 & Zambia & Luangwa Valley & $16 \frac{4}{16}$ & $10 \% / 16$ & $26 \frac{4}{16}$ & 11 \\
\hline
\end{tabular}




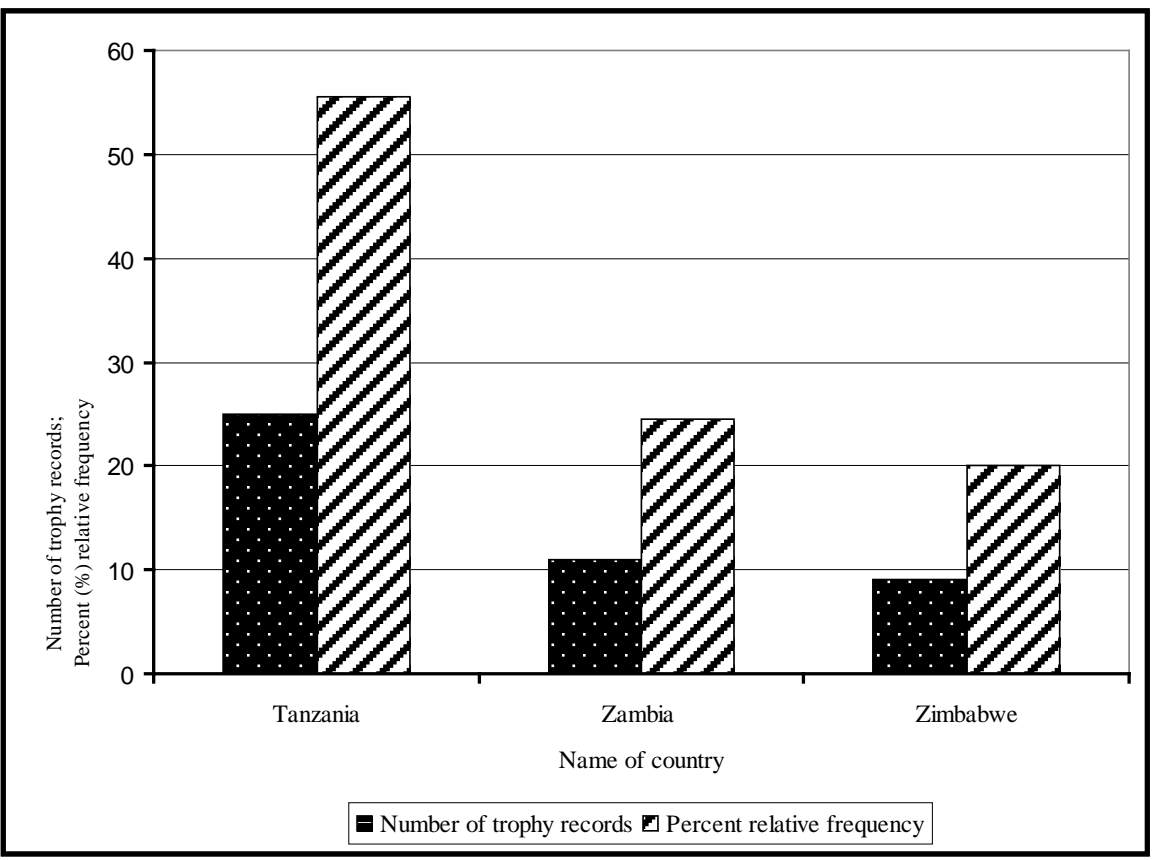

Figure 4. Proportional contributions of lion record trophies to Safari Club International, by Zambia, Tanzania and Zimbabwe.

The lion record trophy contribution was irregular for Zambia, Tanzania and Zimbabwe, being more frequent in some years and absent in others (Figure 4; Table 1). This difference was significant $\left(\chi^{2}=22.65\right.$, DF $=10, \alpha=$ $0.05, \mathrm{P}<0.05$ ) being aggregated in the 1980s and towards the end of the 1990s and almost virtually absent in the late 1960s-1970s (Figure 4).

The regional trend in lion record trophy contribution showed a steady but weak positive increase $(\mathrm{y}=0.0638 \mathrm{x}+$ 0.2784; $\mathrm{R}^{2}=0.1916$ ) mainly spurred by Tanzania (Figure 5).

The trend for Zambia was also positive but much weaker than that of the sub region, $(y=0.0124 x+0.1231$; $\mathrm{R}^{2}=0.0404$ (Figure 5).

Contrary to the popular view, the results showed that the lion record trophy contribution to SCI list of record trophies did not decline for the period 1967-2000 both in Zambia and at sub regional level.

Zambia contributed 11 record lion trophies in the 33 years. The contribution varied from year to year being more frequent in some years than others (Table 1; Figure 5). The highest contribution was in the 1980s and late 1990s. The least contribution was in the 1960s and 1970s when the lion populations were in fact higher than the present time. During the period 1967-2000 Zambia registered a weak but positive increase in the number of lion record trophies suggesting that despite the current low lion populations estimates in Zambia, trophy quality was not negatively affected (Figure 5).

\subsection{Source of Record Trophies}

Regarding popular lion hunting areas in Zambia, it was found that out of the 11 lion record trophies contributed to the SCI list by Zambia seven (7) (64\%) were hunted from the Kafue ecosystem (mainly Mumbwa West GMA) and four (4) (36\%) from the Luangwa Valley ecosystem. Other areas did not contribute any thing. This difference in lion record trophy contribution to the SCI listing between the Kafue and Luangwa Valley ecosystems dispelled the popular belief that the Luangwa Valley is the most important lion hunting area in Zambia (Table 2). Although it has the largest lion population in the country it only contributed 4 of the 11 trophies.

\section{Discussion}

\subsection{Population Size and Trophy Quality}

Results obtained in this study show that despite the low population estimates Professional Hunters (PH) were 


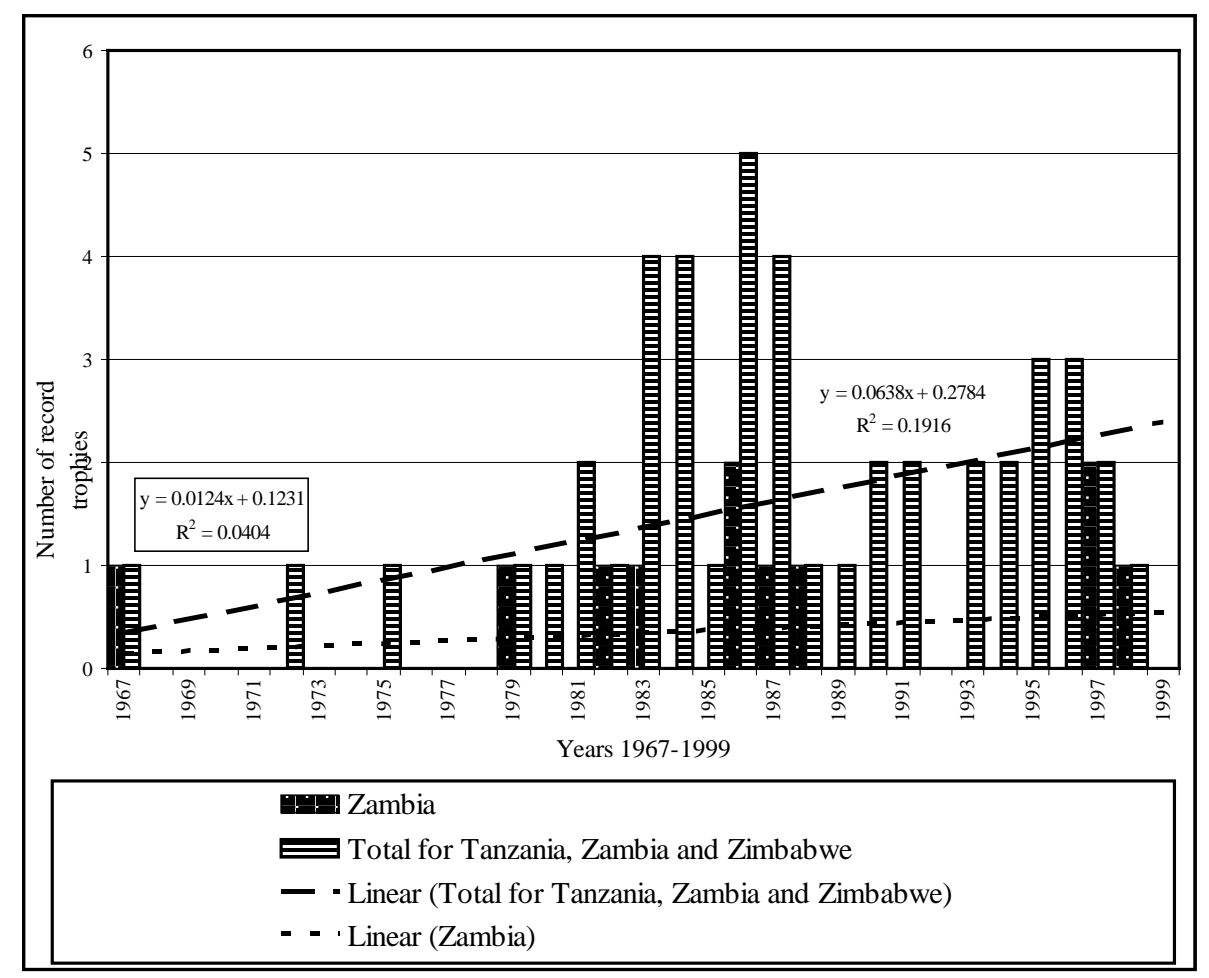

Figure 5. Record of record trophies contributed to Safari Club International and trends for the period $1967-2000$.

Table 2. Number of record trophies, areas from which they were hunted in Zambia for the period 1967-2000.

\begin{tabular}{|c|c|c|c|c|c|c|}
\hline Year & Score & Skull length & Skull width & Rank & Source & Ecosystem \\
\hline 1967 & $2514 / 16$ & 15 13/16 & 10 2/16 & 17 & Mulobezi & Kafue \\
\hline 1979 & 26 & 15 10/16 & $106 / 16$ & 15 & Luangwa Valley & Luangwa Valley \\
\hline 1982 & $262 / 16$ & $1614 / 16$ & 9 13/16 & 13 & Luangwa Valley & Luangwa Valley \\
\hline 1983 & $2514 / 16$ & 15 12/16 & 10 2/16 & 17 & Kafue River/Mumbwa west & Kafue \\
\hline \multirow{2}{*}{1986} & 25 13/16 & 16 & $108 / 16$ & 16 & Mumbwa west & Kafue \\
\hline & $264 / 16$ & 16 6/16 & 10 14/16 & 11 & Luangwa Valley & Luangwa Valley \\
\hline 1987 & $261 / 16$ & $1410 / 16$ & $114 / 16$ & 13 & Mulobezi & Kafue \\
\hline 1988 & $261 / 16$ & 15 14/16 & $103 / 16$ & 14 & Mumbwa West & Kafue \\
\hline \multirow{2}{*}{1997} & $261 / 16$ & 15 6/16 & 10 11/16 & 14 & Mumbwa west & Kafue \\
\hline & 26 10./16 & 16 6/16 & 10 10/16 & 5 & Mumbwa west & Kafue \\
\hline 1998 & $264 / 16$ & $164 / 16$ & $108 / 16$ & 11 & Luangwa valley & Kafue \\
\hline
\end{tabular}

NOTES: Only years when record trophies were registered are shown.

still able to find record male trophies, suggesting genetic implications rather than population size alone. However, it is still important to ensure that lion quotas are sustainable. ZAWA needs to take a precaution on the current increasing proportion of up to $35 \%$ of the hunted lions being sub adults [28]. Implying that there are no controls in the field by ZAWA to ensure that PH's code of ethics is strictly enforced at all times. It is also a warning that perhaps the quotas were too high to sustain the current increasing demand and a down ward adjustment of $>35 \%$ may be necessary. A total ban, though desirable in view of population decline, may not prevent male mortalities through intra-specific fights. As is already known, when the number of male lions increases in a locality, males can fight each other to death, and one would argue that such individuals killed through intra-specific fights could be harvested to raise income for conservation and community projects. So, the current debate on whether to hunt 
or not to hunt lions in Zambia still remains controversial.

The difference in trophy quality between the Luangwa Valley with an estimated population of 2237 and the Kafue ecosystem with 1334 was supported by results obtained by White [28]. She asserted that there could be a genetic difference between the two lion populations. If trophy size was strictly a function of population size, one would have expected a higher proportion of record lion trophies to SCI listing to have come from the Luangwa Valley ecosystem which also has the highest population estimate in the country. This disparity cannot be explained by the current data and perhaps further research would be required to determine the alleged genetic differences.

In light of the above, it was also expected that during the period 1960-1970s when the lion population was much higher than at the present time, Zambia should have contributed more record trophies than in the 1980s and 1990s. It is therefore surprising that the lion record trophy contribution to SCI listing increased when the lion population size was declining. The low proportional contribution in the 1960s-1970s cannot be explained by these results. We also suggest that the current increase in SCI listing (up to 2000) may not be sustained if the population continues to decline.

At regional level, it would appear though, going by the large lion population in Tanzania (which has the largest lion population in the world), that its contribution to SCI listing remained highest and will probably continue to be in the lead until a tipping point has been reached in future. This tipping point in population size at which trophy quality starts to decline is currently not known and requires further research.

\subsection{Speculative Causes of Population Decline}

With these results, it can be speculated that lion trophy hunting alone has not been the cause of the decline in lion populations in Zambia and other countries. Trophy hunting as an activity regulated and monitored by ZAWA would not be responsible for the reduction in lion populations. It is suggested that the likely impact of trophy hunting would be indirect through the selective removal of large males or if trophy hunting selectively takes pride males which often results in a more rapid changeover of pride males. This often results in an increased rate of infanticide within the pride as each new coalition of males frequently kills the cubs that are present. If the rate of change of pride males takes place at intervals of less than about two (2) years for instance, then it is possible to have a situation where successive litters of cubs are being born to the pride, but with the increased likelihood of infanticide, fewer animals are likely to reach maturity and the infanticide that may follow reduce cub survival. Selective hunting of large males but not necessarily older males would also lead to a reduction of males with long and preferably dark mane. The persistence of such selective hunting may perhaps reduce the incidence of such desirable traits in the population promoting the resurgence of males with less or no mane as has been reported in the Luangwa Valley [29].

This phenomenon has been recorded in elephants where the heavy poaching in the late 1970s-1990s for heavy tuskers led to a resurgence of tusk less elephants particularly in the Luangwa Valley. Whether this phenomenon can also apply to the lion is yet unknown.

On the basis of the results obtained in this study, we here suggest that factors characterizing the significant reduction in lion population in Zambia cannot be attributed to lion trophy hunting alone and its use an effective indicator of overall population abundance may be misleading as areas with few lions have yielded more record trophies that areas with higher lion population estimates. It would appear though that there is a tipping point of population estimate below which the number of record trophies may start to decline. Additionally, trophy quality in the field is mainly determined by the mane, yet the Safari Club International system uses a sum of skull measurements, for ranking. Conversely, a large bodied and large -skulled lion can have poor mane, while a small bodied and small skulled lion may have an exceptionally long and often dark mane [30]. The record trophy list therefore, may not be a true reflection of what the hunting clients' desire. Because of the lack of apparent relationship between body size and size of mane, the trophy measurements assessed for Zambia, could also not be used as an affective indicator of population size. It is however, assumed that use of trophy size as an indicator of population size is often based on the understanding that when the population is large, hunters will seek the old and large bodied males. As the population declines and trophy numbers decline, hunters would then take younger males with small skull size or pride males of between 4 - 6 years.

We suggest that in addition to lion trophy hunting and the setting of sustainable lion quotas, ZAWA should also consider other factors such as; human encroachment and loss of habitat in GMAs, loss or reduction of prey 
density to poaching, Problem Animal Control (PAC), snaring, inter and intra specific competition, population isolation and negative perceptions on lion by local communities.

\subsubsection{Encroachment and Destruction of Habitats}

Human encroachment and destruction of habitat particularly in GMAs results in loss of habitat for lion and prey species and increases human-lion conflicts particularly in areas with livestock. Inherent with encroachment is increased incidence of poaching of buffalo and other antelopes, which form the food base for lion. Movement of cattle into GMAs which is often facilitated by tsetse fly eradication is also likely to exacerbate the human - lion conflict as more livestock is introduced in GMAs.

\subsubsection{Decline in Prey Density}

Available evidence indicates that poaching of most prey species and bush meat trade combined with continued reduction in wildlife habitat could be the major factors affecting the growth of wildlife populations in the country [29]. Proliferation of firearms during the liberation struggle in some of Zambia's neighbours exacerbated poaching whilst continued inadequate funding to ZAWA has continued to constrain its anti-poaching capacity, which further contributes to the decline in the population of prey species.

\subsubsection{Problem Animal Control}

Every time there is a suspected problem lion, designated Problem Animal Control (PAC) professionals should investigate the circumstances of livestock loss to assess the best course of action. Alternatives to destroying lions by shooting should include driving away the animal and sensitisation and awareness of the communities. Where livestock is the major source of conflict, communities should be advised and encouraged to restrict livestock from straying into sensitive wildlife habitats of the GMA. The PAC professionals must be able to distinguish between predation of live animals and scavenging of dead ones.

In all cases where investigation proves that lions have attacked a person, the lions should be removed at the first opportunity irrespective of the circumstances of the attack. It is important that every effort is made to establish which lions are responsible for undesirable activities before any attempt to eliminate them is undertaken. Investigation and removal should be followed by education to minimize future problems.

\subsubsection{Conflict with Livestock and Public Attitude}

In pastoral areas, livestock-lion conflicts have resulted in increased negative attitude and low tolerance levels towards the lion. This sometimes leads to total extermination of the species as the case was on the Kafue Flats ecosystem. Increased livestock populations in GMAs will undoubtedly increase incidences of both livestock-lion and human - lion conflicts. In most cases, local communities have responded to these conflicts by poisoning the lion as part of their own PAC programme.

\subsubsection{Poaching/Snaring}

Lion poaching is not common as most local communities poach for meat. However, lions often get caught up in wire snares set to catch antelope species. In most cases, lions that have survived snaring become a menace to livestock and humans as they are in most cases no longer able to hunt game. Consequently, ZAWA has opted to kill such lions under its PAC programme as such lions are of little value to the trophy hunting industry.

\subsubsection{Inter- and Intra-Specific Competition}

Studies such as those by Purchase [31] [32] on lion feeding behaviour have shown a high degree of dietary overlap between lion and hyaena. Prides lacking males are particularly prone to kleptoparasitism from hyaena, and high numbers of hyaena can suppress lion population under such circumstances. Unsustainable harvesting of pride males may expose prides to high levels of kleptoparasitism. A quick turn over of males in a pride would also slow down the population growth rate as new males have the tendency of killing cubs sired by the previous males.

\subsubsection{Population Isolation}

Destruction of wildlife corridors has resulted in most protected areas becoming ecological islands. Isolated populations in the long term experience loss of genetic variability [29]. 


\subsubsection{Negative Value Placed on the African Lion}

Continued loss of livestock and human life has compelled local communities to consider the African lion as a vermin that needs to be exterminated despite its tourism value and community income from lion trophy hunting, which benefits communities in areas with CBNRM, programmes. Livestock as a private resource is considered more valuable both at individual and society levels compared to the lion, a public resource. Consequently, more value is placed on livestock compared to the lion.

\section{Conclusions}

The current results on the alleged impact of lion trophy hunting on population estimates do not seem to suggest any significant negative impact on population size as the size of skulls collected did not differ significantly.

In the absence of empirical data, it is difficult to ascertain the actual impact of trophy hunting on the lion population in Zambia, although it would be logical to suggest that trophy sizes will decline in future if the population continues to decline. It is however, generally accepted that unregulated trophy hunting would on a longterm have negative impact on the species population through removal of pride males resulting in increased rate of infanticide within the pride. In areas with significantly higher hyena populations removal of pride males could result, as shown by studies elsewhere, into strong inter-specific competition between the lion and hyena for food. Lionesses are easily dominated by groups of hyena and it is generally the pride males, which defend the prides from the hyaena. If males are over hunted, killed as problem animals or caught in wire snares, lionesses may be out-competed by strong hyena clans. This may have been one of the reasons for the disappearance of the Liuwa plain lions in west Zambezi Upper Game Management Area.

In PAC, the first and most effective response should be to inform rural people on the best means of protecting livestock and human life from predators, before a problem arises. In most cases, improved livestock management practices can dramatically reduce depredation, while knowledge on the ecology and behaviour of particular carnivores can prevent loss of human life and livestock. Education and knowledge is cheaper and more effective in the long term than is repetitive PAC intervention. At a general level, we would expect people to be more prepared to take preventative action in areas where wildlife contributes to their financial well-being through tourism.

Translocation may be used as an alternative under certain circumstances. The caution however, is that translocation of trapped problem predators may not be successful particularly when it leads to suffering and death. Lions, leopards and hyenas are territorial; strangers translocated into "suitable" habitat are often chased and killed by residents. If they escape from or avoid resident animals, they will generally be re-displaced and try and find their way home, often taking livestock along the way. If caught in cage traps, it is likely that they will damage their claws and teeth while trying to escape, making them less able to hunt and defend themselves in the wild. Further research is suggested in this area of conservation.

\section{Acknowledgements}

We wish to thank the Zambia Wildlife Authority management for supporting and encouraging this study and for the PHAZ and Safari Operators in providing various data.

\section{References}

[1] McCarthy, T. (2004) Nowhere to Roam. Time Magazine, 44-53.

[2] Bauer, H. and Van Der Merwe, S. (2002) The African Lion Database. The African Lion Working Group, IUCN/SSC, Gland.

[3] Chardonnet, P. (2002) Conservation of the African Lion: Contribution to a Status Survey. International Foundation for the Conservation of Wildlife, France and Conservation Force, Washington DC, 169 p.

[4] Nowell, K. and Jackson, P. (1996) Wild Cats. Status Survey and Conservation Action Plan. IUCN/SSC Cat Specialist Group. IUCN, Gland, 382 p.

[5] Frank, L. and Packer, C. (2003) Life without Lions. New Scientist.

[6] IUCN (2006) Eastern and Southern African Lion Conservation Strategy Workshop Minutes Report, Johannesburg, 11-13 January 2006, $44 \mathrm{p}$.

[7] Smallwood, K.S. and Schonewald (1996) Scaling Population Density and Spatial Pattern for Terrestrial, Mammalian 
Carnivores. Oecologia, 105, 329-335.

[8] Smallwood, K.S. and Schonewald, C. (1998) Study Design and Interpretation of Mammalian Carnivore Density Estimates. Oecologia, 113, 474-491.

[9] Fuller, T.K. and Sievert, P.R. (2001) Carnivore Demography and the Consequences of Changes in Prey Availability. In: Gittleman, J.L., et al., Eds., Carnivore Conservation, Cambridge University Press, Cambridge, 163-168.

[10] Packer, C. (1986) The Ecology of Sociality in Felids. In: Rubenstein, D.I. and Wrangham, R.W., Eds., Ecological Aspects of Social Evolution: Birds and Mammals, Princeton University Press, Princeton, 429-452.

[11] Neo-Mahupeleng, G., Dimakatso, T., Imakatso, H., Andreasssen, H. and. Wegge, P. (2001) Population Structure, Group Dynamics, Home Ranges and Habitat Use of Lions (Panthera leo) in Northeast Chobe National Park, Botswana. In: Moggae, F., et al., Eds., National Technical Predator Management and Conservation Workshop in Botswana, Gaborone, 1-30.

[12] Packer, C., Hilborn, R., Mosser, A., Kissui, B, Borner, M., Hopcraft, G., Wilmshurst, J., Mduma, S. and Sinclair, A.R.E. (2005) Ecological Change, Group Territoriality, and Population Dynamics of Serengeti Lions. Science, 307, 390-393.

[13] Mitchell, B.L., Shenton, J.B. and Uys, J.C.M. (1965) Predation on Large Mammals in the Kafue National Park, Zambia. Zoology, 1, 297-318.

[14] Schaller, G.B. (1996) Carnivores and Conservation Biology. In: Gittleman, J.L., Ed., Carnivore Behavior, Ecology, and Evolution, Vol. 2. Comstock Publishing Association, Cornell University Press, Ithaca, 1-10.

[15] Gittlemann, J.L., Funk, S.M., Mcdonald, D. and Wayne, R.K. (2001) Carnivore Conservation. Cambridge University Press, Cambridge.

[16] Grisham, J. (1994) Conservation Assessment and Management Plan for Canids, Hyaenas, and Aardwolves. Meeting of the Canids, Hyaenas and Aardwolf Taxon Advisory Group, Oklahoma City Zoological Park, Oklahoma City.

[17] Sinclair, A.R.E. and Arcese, P. (1995) Serengeti II. Dynamics, Management, and Conservation of an Ecosystem. University of Chicago Press, Chicago, 665 p.

[18] Whitman, K.L. (2002) Safari Hunting of Lions: A Review of Policies, Practices, and Industry Concerns. In: Proceedings of the 2nd Meeting of the African Lion Working Group, Brandhof, 9-10 May 2002, 111-124.

[19] Packer, C. and Pusey, A.E. (1984) Infanticide in Carnivores. In: Hausfater, G. and Hrdy, S.B., Eds., Infanticide: Comparative and Evolutionary Perspectives, Aldine, New York, 31-42.

[20] Caro, T.M., Pelkey, N., Borner, M., Severre, E.L.M., Campbell, K.L.I., Huishsa, S.A. J., Olekuwai, J., Farm, J.P.B. and Woodworth, B.L. (1998) The Impact of Tourist Hunting on Large Mammals in Tanzania: An Initial Assessment. African Journal of Ecology, 36, 321-346.

[21] Packer, C. (2000) Infanticide is no fallacy. American Anthropologist, 102, 829-830.

[22] Whitman, K., Starfield, A.M., Quadling, H.S. and Packer, C. (2004) Sustainable Trophy Hunting of African Lions. Nature, 428, 175-178.

[23] Spong, G. and Creel S. (2001) Deriving Dispersal Distances from Genetic Data. Proceedings of the Royal Society of London, B, 268, 2571-2574.

[24] Spong, G., Stone, J., Creel, S. and Bjorklund, M. (2002) Genetic Structure of Lions (Panthera leo L.) in the Selous Game Reserve: Implications for The evolution of Sociality. Journal of Evolutionary Biology, 15, 945-953.

[25] Kays, R.W. and Patterson, B.D. (2002) Mane Variation in African Lions and Its Social Correlates. Canadian Journal of Zoology, 80, 471-478.

[26] West, P.M. and Packer C. (2002) Sexual Selection, Temperature, and the Lion’s Mane. Science, 297, 1339-1343.

[27] Yamaguchi, N., Cooper, A., Werdelin, L. and MacDonald D.W. (2004) Evolution of the Mane and Group-Living in the Lion (Panthera leo): A Review. Journal of Zoology, London, 263, 329-342.

[28] White, P. (2009) Report on the Development of a Field Based Manual to Aid Lion Age Determination in the Field. Zambia Wildlife Authority. Unpublished Report.

[29] Chansa, W., Simukonda, C., Sichone, P.M. and Zyambo, F.C. (2010) Zambia’s Conservation Strategy and Action Plan for the African Lion. Zambia Wildlife Authority, New Horizon Printing Press, Lusaka.

[30] SCI (2000) The Safari Club International Record Book of Trophy Animals for Africa, North America, South America, Europe, Asia and the South Pacific. Tuckson, Arizona.

[31] Purchase, K.G. (2004) Factors Affecting the Ratio of Lions (Panthera leo) to Spotted Hyaenas (Crocuta crocuta) in Protected Areas of Africa: Competition and /or Available Prey. Ph.D. Thesis, University of Aberdeen, Aberdeen.

[32] Attwell, C.A.M. and Viljoen P.C. (2000) Lions and Lion Hunting in Zambia: Management Guidelines. Unpublished Report for Zambia Wildlife Authority. International Conservation Services, Nelspruit, 1-82. 